\title{
PLXND1 wt Allele
}

National Cancer Institute

\section{Source}

National Cancer Institute. PLXND1 wt Allele. NCI Thesaurus. Code C114411.

Human PLXND1 wild-type allele is located in the vicinity of 3q22.1 and is approximately 52

kb in length. This allele, which encodes plexin-D1 protein, plays a role in semaphorin-

mediated signaling. 